\title{
MEMÓRIA HISTÓRICA DA PÓS-GRADUAÇÃO
}

\author{
GRADUATE STUDIES: A BRIEF REVIEW
}

Dalmo de Souza Amorim ${ }^{1}$

${ }^{1}$ Professor Titular, aposentado. Departamento de Clínica Médica da FMRP-USP.

Este relato - que perpassa o campo semântico de reflexões, caderno de apontamentos, lembrete - conciso, tem origem no acervo de dados de memória, de apontamentos e de documentos selecionados e direcionados para o fim de contribuir para o resgate da história do nosso departamento.

O relato deve ser aceito como tal - reconstrução interpretativa - de um período que, por conveniência expositiva, diz-se dos primórdios. Ele poderá ser assim tido se nos referirmos a um sistema educacional que se instalava; poderá, também, ser designado de transição no âmbito do departamento, se nos reportarmos à existência de outro sistema educacional pré-existente.

A função desta exposição não é a de estabelecer contraste com as fases que precedem e nem tampouco com as que sucedem àquele período de implantação da pós-graduação stricto sensu. Se se permite atribuir função a este relato é a de oferecer interpretação para os primórdios e, eventualmente, para as mudanças que a partir dela se estabelecem nos dois sistemas de ensino.

Não vou lidar com números. Vou ocupar-me com o que me parece ser a essência do novo sistema educacional: o conceito de Área, os recursos existentes e a organização dos estudos no novo sistema acadêmico.

\section{Os idos da pós-graduação}

Não vou deter-me, por ocioso, nas origens e objetivos da pós-graduação objeto desta exposição.

Mas cabe referir que o sistema organizado de pós-graduação começou, efetivamente, nos Estados Unidos em 1861, quando a YaIe University conferiu o primeiro título de Doutor nos moldes das universidades alemãs.
O objetivo fundamental do sistema na universidade americana é a formação de cientistas, professores, pesquisadores, bem como o treinamento de pessoas para solucionar problemas gerados na complexidade da estrutura social. O modelo norte-americano tem características do tipo empresarial, voltado para as necessidades da comunidade e utiliza-se dela como fonte de recursos para retorno, sob a forma de manutenção e elevação dos padrões de ciência e tecnologia.

Entre nós, nas décadas de 50 e 60 , o funcionamento tecnológico proporciona as condições necessárias para a geração da teoria do capital humano, o qual enfatiza a função técnica da Educação. O depoimento de Anísio Teixeira, no crepúsculo dos anos sessenta, na Câmara de Estudos para a Reestruturação do Ensino Superior, é expressivo quanto aos debates travados nas duas décadas anteriores.

Posso destacar dois pontos que nos auxiliam na discussão:

- a estrutura organizacional do ensino superior: a clivagem ensino-pesquisa, colocando em campos opostos professores e estudantes mais voltados para as áreas de Ciências Humanas e aqueles outros das escolas profissionais (e.g., Direito, Engenharia e Medicina);

- o tipo de conteúdo do ensino: convencional, fragmentado, enciclopédico, repetitivo e pouco vinculado à pesquisa, típico da formação das escolas profissionais.

Era claro que precisávamos de novas lideranças capazes de produzir novas experiências no ensino superior, rompendo a clivagem ensino-pesquisa. Ao abordar as matrizes ideológicas, na Clínica Médica, realça a figura do Prof. Hélio Lourenço de Oliveira. 
É preciso ter presente que a nossa primeira Lei de Diretrizes e Bases da Educação Nacional só viria a ser sancionada em dezembro de 1961 (Lei 4024/61).

A partir dela o país examina os seus programas (e.g., educação e saúde). A esse respeito a principal característica da ação do poder público nacional foi a de definir uma política operacional de acordo com as condições sociopolítico-educacionais prevalentes naquele momento (o governo brasileiro era considerado de esquerda). Já nos referimos às vozes de educadores nacionais cujo ápice é o depoimento de Anísio Teixeira. Por exemplo, na conjuntura dominante, na Saúde, a política de formação de recursos humanos visava a criação de categorias especializadas para o mercado de trabalho, desvinculadas de formação teórico-pedagógica.

$\mathrm{O}$ aspecto de realidade a considerar é a de que nas áreas de aplicação a demanda de profissionais especializados se fazia sentir agudamente no mercado de trabalho. Mas, ao mesmo tempo, a geração de capital humano para atender às necessidades do funcionamento tecnológico carecia de um outro sistema educacional. Disso decorre a necessidade de um sistema de estudos após a graduação.

Segundo a conceituação lançada por Newton Sucupira, no Parecer 977/65, posteriormente consagrado por toda a legislação, os cursos realizados após a graduação foram classificados em dois grandes grupos. O primeiro é o da pós-graduação stricto sensu que conduz aos graus acadêmicos de Mestre e Doutor e que foi regulamentado pelo Parecer 77/69. O segundo, denominado lato sensu, compreende aperfeiçoamento, especialização, extensão e outros.

A caracterização definia as diferenças de objetivos dos dois sistemas acima referidos. A pós-graduação stricto sensu visa criar uma elite científico-cultural criativa de professores e pesquisadores de alto nível para a solução de novos problemas. A pós-graduação lato sensu visa o preparo e o aperfeiçoamento para o exercício profissional qualificado.

No debate e embate das idéias, que então se estabeleceu, foi apregoado que a pós-graduação acadêmica nas áreas de aplicação não poderia prescindir de base profissionalizante. Por exemplo, foi dito que o ensino médico tem tais peculiaridades que reclama ajustes aos preceitos e normais gerais reguladoras da pós-graduação stricto sensu.

Para disciplinar a pós-graduação stricto sensu, na área médica, foi publicado o Parecer 576/70. Era pouco. Já estávamos organizados quando o Diá- rio Oficial do Estado de São Paulo publica, aos 18 de dezembro de 1970, a Norma $\mathrm{n}^{\circ} 5$, que atrelava a pós-graduação aos programas de residência.

Reza aquela norma que o cumprimento obrigatório da Residência Médica, no Regime de Dedicação Exclusiva, com duração mínima de doze meses, incluirá estágio rotativo nos serviços gerais do Hospital, compreendendo Anatomia Patológica, Radiologia, Laboratório Clínico, Anestesiologia e Hemoterapia.

Não se imagine que essas mudanças eram inocentes. Elas nos custavam defender uma matriz ideológica que se contrapunha a posições corporativas. Esses embates vieram à luz durante o Simpósio Nacional de Pós-Graduação nas Áreas Biomédicas, aqui realizado em 1975.

Surpreenderam-nos as normas complementares na pós-graduação stricto sensu na área médica. Entendo como impertinente a designação de curso e não de programa de pós-graduação. De curso, viés da graduação convencional, com organização curricular e coletiva, não falávamos. De programas, em sistema tutorial e individualizado, lidávamos. É até mesmo extravagante que artigo no Parecer 576/70 torna obrigatória a participação do aluno em trabalhos de pesquisa. Como se a obtenção dos títulos acadêmicos, na pós-graduação stricto sensu, pudesse ser alcançada sem a realização daquelas.

As razões para a obstinada oposição aos programas de pós-graduação stricto sensu, em medicina, eram notórias.

Em primeiro lugar a tradição de conceder o título de doutor ao bacharel de curso médico. Cabe notar que, durante a graduação, ensino e pesquisa estão dissociados. Em segundo lugar, há cerca de cinco décadas, a graduação é complementada por treinamento em serviço, na Residência Médica. Finalmente, o título de Livre-Docente era o mais destacado na carreira acadêmica (descartados os concursos de cátedra, extinto com a reforma do ensino superior - Lei ${ }^{\circ} 5540 / 68$ ).

\section{A pós-graduação na FMRP}

O primeiro Boletim de Pós-Graduação (19711972) abre com o seguinte título "Tradição de Ensino e Pesquisa na Faculdade de Medicina de Ribeirão Preto".

O preâmbulo do Boletim destaca como condições favoráveis para o êxito desses programas, aqui: - a organização departamental;

- o regime único de trabalho de dedicação exclusiva à docência e à pesquisa; 
- a identidade fundamental de propósitos e a intimidade entre os centros de ensino e de pesquisa nas áreas básicas e os centros clínicos.

Em favor dessa afirmação, pode-se apontar que, apesar de haver iniciado as suas atividades em 1952, já em 1955 haviam sido defendidas três teses de doutoramento. Este número se eleva para 115, no ano de 1970, por ocasião da aprovação de nossos programas de pós-graduação stricto sensu. Até o ano de 1979, quando expira o direito daqueles já inscritos no sistema antigo, foram 149 as teses de doutorado defendidas: 62 em departamentos básicos e 87 em departamentos clínicos.

Este relato recomenda a abordagem de dois pontos, que podem ser comparados com a evolução ocorrida desde a implantação:

- os programas de pós-graduação tinham o objetivo - hoje chamaríamos o perfil — de formar professores e pesquisadores para atender as demandas de outras instituições de ensino superior e de pesquisas biomédicas;

- o mercado de trabalho. O Boletim aborda explicitamente o assunto. Não o mercado de trabalho profissional, mas o mercado de trabalho de professores e pesquisadores. Diz o Boletim da Pós-Graduação que essa necessidade derivava da grande expansão dos cursos médicos (eles eram então 75) cujo funcionamento já havia sido aprovado.

"Calculamos", reza o documento, "que do total de docentes que temos necessidade, apenas 01 por cento são formados anualmente pelas nossas universidades. Admitido um número mínimo por departamento, pôde-se calcular que o déficit de docentes deve andar por alguns milhares".

\section{Das qualidades e limitações}

Se é verdade que tínhamos todas essas vantagens, devemos examinar o que seriam as limitações ou qualidades relativas:

- a Comissão de Pós-Graduação era integrada por pessoas de reconhecida experiência em pesquisa, com destaque para a figura de Maurício Rocha e Silva. Nenhum, no entanto, tinha vivência em um sistema educacional dessa natureza. De fato o que se possuía era um conjunto de normas e regulamentos;

- a compreensão, aceitação e funcionamento como Área, ente abstrato. O sistema preconizado na pósgraduação stricto sensu é interdepartamental, multidisciplinar e interdisciplinar.
O pressuposto básico é aquele que não estamos lidando com coleção de conhecimentos ("disciplinas"), representativos de categorias profissionais ("especialidades"), mas sim nos ocupando com uma "unidade acadêmica" (e.g., Área de Concentração Clínica Médica).

Nenhum candidato a mestrado ou doutorado, diziase, poderá completar a sua formação acadêmica, isto é, juntar o número de créditos exigidos dentro de uma única Área. A premissa é a de que deveriam ser oferecidos créditos outros, em domínio conexo, de modo a permitir a organização coerente do programa de estudos de cada aluno;

- tínhamos, sim, pessoal titulado e recursos laboratoriais. Em meu entender, no entanto, mudou a situação do docente titulado: o professor deve assumir função tutorial, cuja marca maior é o de guia de estudos individuais. A disponibilidade de recursos é para o atendimento das pesquisas do próprio pessoal docente das disciplinas; esses recursos eram limitados diante de demanda ampla e crescente.

\section{A Clínica Médica}

Na hierarquia das decisões, os fundamentos, nos departamentos, deveriam ser os mesmos correspondentes aos preceituados pela Comissão de Graduação da FMRP. Os fundamentos, sim. Talvez os processos, não.

A nós, parecia não ser exercício difícil porque tínhamos posse dos meios. Dizia o nosso documento (Área de Concentração Clínica Médica, 1971): “...a natureza do pessoal docente, os recursos intrínsecos e o trabalho já realizado no campo do ensino e da pesquisa médica garantem o atendimento dos três motivos fundamentais da pós-graduação:

- formar professorado competente que possa atender à expansão quantitativa de nosso ensino superior;

- estimular o desenvolvimento da pesquisa científica por meio da preparação adequada de pesquisadores;

- assegurar o treinamento eficaz de técnicos e trabalhadores intelectuais do mais alto padrão".

A bem da verdade, nunca ninguém soube o que esse último motivo queria dizer.

Mas a transposição de Departamento para Área era mais do que um exercício semântico: era preciso converter uma realidade (o Departamento, com múltiplas disciplinas não integradas) em uma abstração (a Área), uma construção do espírito, com uma organização de conteúdos curriculares distinta da até então. 
Como construir uma "unidade acadêmica" que possuísse as características pretendidas da interdisciplinaridade no conceito básico da pós-graduação stricto sensu?

Havia dualidade departamental, situação conflituosa à vista da prática do ensino (e outras funções) por especialidades dissociadas e fragmentadas. Era tentador, e talvez de mais fácil compreensão, criar cursos, por especialidades, com o suposto aprofundamento do saber. Para ir ao encontro do conceito básico, a solução encontrada foi a criação de uma "unidade temática": Fisiopatologia e Clínica, perpassando as diferentes subáreas ("disciplinas" de especialidades).

Tendo em conta o perfil do pós-graduando era necessário estabelecer um "núcleo" de certa identidade em cada "subunidade temática". Assim, cada uma delas deveria conter elementos relativos à fisiopatologia, aos métodos especiais de investigação e o estudo de doenças que constituíssem exemplos de alterações patológicas e fisiopatológicas daquele sistema ou órgão.

Esse núcleo era complementado pelo oferecimento de outras disciplinas - no âmbito da Área e fora dela — de modo a permitir a construção dos programas de estudo individuais. Era lógico que as disciplinas complementares deviam guardar coerência com a organização do programa de estudos daquele aluno individual.

Contudo, como o oferecimento dessas disciplinas complementares dependia da disposição e boa-vontade do docente por elas responsáveis (e nem sempre isso ocorria), resultaram sérias distorções na elaboração dos programas individuais. Esses desvios mereceram observações críticas durante o Simpósio Nacional de Pós-Graduação nas Áreas Biomédicas, que qualificou como caça aos créditos essas distorções.

Outra dificuldade encontrada é aquela relativa aos Exames Gerais de Qualificação. Ao adotarmos o modelo norte-americano, importamos também o modo de verificação da integração dos conhecimentos e sua coerência com o objeto da dissertação ou tese. Esse exame é tido como comprehensive examination, por sua abrangência.

Dado o histórico disciplinar da graduação, o que inclui a performance de cada professor, e apesar da criação de uma "unidade temática integradora", os Exames Gerais de Qualificação não eram abrangentes. Havia repetição da avaliação já ocorrida quando do transcurso do aluno por cada disciplina. A redundância causou, na época, acerbadas reclamações dos alunos.

Finalmente, os recursos físicos. Acreditávamos ter os recursos para o desempenho das novas atribuições, tínhamos, sim, para atender as necessidades até então correntes. Mas não as tínhamos para um sistema em demanda crescente.

Desde 1974, após a formatização do reconhecimento de seus programas de pós-graduação strícto sensu, no Conselho Federal de Educação, o Departamento pleiteava recursos orçamentários extraordinários para o desenvolvimento científico e a formação de professores. Falava-se da formação de recursos humanos no âmbito do conceito que embasava os programas. Tratava-se do primeiro financiamento, pelo poder público, em área de aplicação médica.

Era financiamento a "custo zero", sem "cobrança de produção" no que essa possa ser representada pelos aspectos quantitativos de titulações e publicações. Em outras palavras: o Departamento tinha o "crédito da competência" já adquirida. Ele era usado como "modelo".

Programa financeiro que contemplava todo o Departamento foi aprovado em 1977 pela Financiadora de Estudos e Projetos (FINEP), com recursos complementares da Secretaria de Estado da Cultura, Ciência e Tecnologia. Por razões estranhas a nós, a FMRP não aceitou a concentração de recursos daquela Secretaria em uma área que expandia o Laboratório Experimental da Clínica Médica.

As renovações posteriores de contrato com a FINEP, além de lentos e descontinuados, viriam alterar a característica básica do programa e direcionar o financiamento para alguns projetos considerados prioritários por aquela financiadora. 